\title{
Effects of Inoculum Dose, Temperature, Cultivar, and Interrupted Leaf Wetness Period on Infection of Boxwood by Calonectria pseudonaviculata
}

H. F. Avenot, Department of Plant Pathology, Physiology and Weed Science, C. King, Laboratory for Interdisciplinary Statistical Analysis, and T. P. Edwards and A. Baudoin, Department of Plant Pathology, Physiology and Weed Science, Virginia Tech, Blacksburg 24061; and C. X. Hong, Department of Plant Pathology, Physiology and Weed Science, Virginia Tech, Hampton Roads Agricultural Research and Extension Center, Virginia Beach 23455

\begin{abstract}
Boxwood blight is an emerging disease of great concern for the ornamental horticulture industry, historic garden managers, landscapers, and homeowners. Controlled-environment experiments were conducted to determine the effects of conidial concentration, temperature, interrupted leaf wetness period, cultivar, and leaf age on infection of boxwood leaves by Calonectria pseudonaviculata. Boxwood blight incidence (BBI) increased with increasing concentration up to $2.0 \times 10^{4}$ spores $/ \mathrm{ml}$. BBI also increased as temperature increased from 18 to $25^{\circ} \mathrm{C}$, then declined gradually to zero at $29^{\circ} \mathrm{C}$. Similar infection effects of inoculum concentration were observed in an experiment with four boxwood cultivars ('Justin Brouwers', 'John Baldwin', 'Green Mound', and 'Nana') of various degrees of susceptibility. The hypothesis that younger leaves are more susceptible than

older leaves was supported for Justin Brouwers and Nana but not for Green Mound; and younger leaves of John Baldwin were less susceptible than older leaves. When inoculated plants ('Suffruticosa') were exposed to dry interruptions of $3 \mathrm{~h}$ or longer between 5 or $8 \mathrm{~h}$ of initial wetness and $12 \mathrm{~h}$ of additional wetness, these plants had significantly lower BBI compared with those exposed to continuous wetness for $20 \mathrm{~h}$, and similar or at most slightly more infection than plants exposed to only the 5- or 8-h initial wetness. Continuous wetness durations beyond $20 \mathrm{~h}$ did not increase infection in these experiments. These results advanced our understanding of the environmental requirements of the infection process in boxwood blight development and they are essential for refining disease forecasting models.
\end{abstract}

Calonectria pseudonaviculata $($ syn. = Cylindrocladium pseudonaviculatum and C. buxicola) causes "boxwood blight" in Buxus spp. (Crous et al. 2002; Henricot and Culham 2002; Henricot et al. 2012). Boxwood blight was first discovered in a nursery in Hampshire, United Kingdom (Henricot and Culham 2002; Henricot et al. 2000) and New Zealand (Crous et al. 2002; Ridley 1998) and since then has spread throughout Europe (Henricot et al. 2008). This disease was detected in Connecticut and North Carolina of the United States in 2011, infecting a number of Buxus spp. and resulting in significant losses in container and field-grown nurseries (Douglas 2012; Ivors et al. 2012a). At present, it has been detected in at least 21 states and three Canadian provinces (British Columbia, Ontario, and Québec) (Elmhirst and Auxier 2013; Iriarte et al. 2016; Ivors et al. 2012a; Malapi-Wight et al. 2014; WardGauthier et al. 2016). Symptoms of boxwood blight include brown to black circular lesions on leaves that often have a yellow halo, dark margin, and necrotic center and the formation of black stripes on stems. The pathogen causes defoliation and dieback, rendering infected plants unsuitable for sale. In addition, severe damage occurs in infected landscape plantings, detracting from the aesthetics of gardens (Dart et al. 2014; Henricot et al. 2008; Ivors et al. 2012a).

Current approaches to managing this disease include inspection, sanitation, cultural controls, fungicide application, and planting of less susceptible cultivars (Dart et al. 2012; Ganci et al. 2013; Henricot et al. 2008; LaMondia 2014). Over 95 species of Buxus are known (Van Laere et al. 2011) and recent screening of diverse host germplasm for pathogen resistance has revealed various levels of susceptibility

Current address of C. King: Research Statistician, Sandia National Labs, Albuquerque, NM.

Corresponding authors: H. F. Avenot; E-mail address: hfavenot@gmail.com; and A. Baudoin; E-mail address: abaudoin@ vt.edu

*The $\boldsymbol{e}$-Xtra logo stands for "electronic extra" and indicates that one supplementary file and three supplementary tables are published online.

Accepted for publication 12 January 2017.

() 2017 The American Phytopathological Society of different Buxus spp. and cultivars to boxwood blight (Douglas 2012; Ganci 2014; Gehesquière 2014; Henricot et al. 2000, 2008; Shishkoff et al. 2015). In general, Buxus sempervirens cultivars were the most susceptible and other cultivars were ranked as either susceptible, moderately susceptible, moderately tolerant, or tolerant (Ganci et al. 2013; Gehesquière 2014; Shishkoff et al. 2015). The efficacy of several groups of fungicides has been evaluated (Baudoin et al. 2015; Ganci et al. 2013; Gehesquière et al. 2013; Henricot et al. 2008; Henricot and Wedgwood 2013; Ivors et al. 2012b; LaMondia 2014, 2015).

Understanding the factors affecting the development of plant disease epidemics is essential to the design and implementation of effective disease management strategies (De Wolf and Isard 2007). There have been a few reports about the biology of Calonectria pseudonaviculata and the epidemiology of the disease with regard to environmental requirements for conidial germination, mycelial growth, infection of boxwood leaves, and dispersion patterns (Dart et al. 2015; Gehesquière 2014; Gehesquière et al. 2013; Henricot 2006). The pathogen has been described as a low-temperature fungus because it can grow below $10^{\circ} \mathrm{C}$; it has a temperature optimum below $25^{\circ} \mathrm{C}$ and maximum below $30^{\circ} \mathrm{C}$ (Henricot 2006; Henricot and Culham 2002). The infective propagules of $C$. pseudonaviculata are conidia. Its infection cycle may be completed in less than 1 week, with conidial germination beginning $3 \mathrm{~h}$ after inoculation, penetration occurring $5 \mathrm{~h}$ after inoculation through stomata on the lower surface of leaves or directly through the cuticle, and new spores produced within 7 days (Henricot 2006; Henricot et al. 2008). The fungus also produces resting structures called microsclerotia (Weeda and Dart 2012), which can survive for years in decomposing leaf debris (Dart et al. 2015; Ganci 2014; Henricot et al. 2008). These structures germinate to form conidia, which serve as a source of initial inoculum for disease epidemics (Dart et al. 2015; Weeda and Dart 2012). Primary infection from windborne spores appears unlikely due to their sticky nature and, hence, spores are most likely water-splashed or directly transferred to plants by contaminated animals, tools, or other agents (Gehesquière et al. 2013; Henricot 2006). Secondary inoculum is produced on lesions on boxwood twigs or leaves.

As with many plant diseases, infection is a major component of boxwood blight epidemics influenced by the environment; however, information on how inoculum dosage and environmental factors contribute to the disease development is limited. Gehesquière (2014) 
demonstrated that boxwood blight development, as measured by the number of diseased leaves per plant, increased with increasing temperature from 6 to $22.4^{\circ} \mathrm{C}$ and continuous wetness from $6 \mathrm{~h}$ to 7 days. These results have been the major basis for developing a disease prediction system that is being tested (Coop 2013). To bridge data gaps for boxwood blight infection under warmer temperatures (above $22.4^{\circ} \mathrm{C}$ ), the Coop model set the upper limit for infection at $29.4^{\circ} \mathrm{C}$ because this fungus had restricted in vitro growth at $27.5^{\circ} \mathrm{C}$ and no growth at $30^{\circ} \mathrm{C}$ (Henricot and Culham 2002). This upper temperature limit for infection is yet to be validated, and a number of other important questions must be experimentally addressed in order to improve the reliability and application of this disease forecasting model. For example, what is the optimal temperature for infection? How may warm temperatures affect infection rate? How may interrupted wetness affect disease initiation and progression? How do boxwood plants respond to different levels of inoculum dose? These questions are particularly important for boxwood production regions such as southeastern United States with warm, humid summers.

The objective of this study was to fill these knowledge gaps by investigating the effects of inoculum dosage, warm temperature, and interrupted wetness on the infection of boxwood plants by C. pseudonaviculata under controlled conditions. The impact of cultivar and leaf age was also assessed on four cultivars of different susceptibility to the disease.

\section{Materials and Methods}

Plants. All boxwood plants used in this study were supplied by Saunders Brothers Nursery in Piney River, VA. They were transplanted to $10-\mathrm{cm}^{2}$ pots (a single plant per pot) in potting mix consisting of 56\% composted pine bark, 32\% horticultural grade coarse perlite, and $12 \%$ peat moss. For the experiment on the effects of inoculum concentration, temperature, and dry periods on infection, 2-year-old highly susceptible $B$. sempervirens 'Suffruticosa' plants were used. Susceptibility estimates were based on Ganci (2014) and Gehesquière (2014). For the experiment on the effects of inoculum dose, cultivar, and leaf age, four cultivars with various degrees of susceptibility to boxwood blight (Ganci 2014) were included. The highly susceptible 'Justin Brouwers', traditionally known as B. sinica var. insularis or B. microphylla but recently reclassified as belonging to the B. sempervirens group (Van Laere et al. 2011), was selected, as well as three less susceptible cultivars; namely, Buxus X 'Green Mound' (moderately susceptible), B. microphylla 'John Baldwin' (moderately tolerant), and B. sinica var. insularis 'Nana' (tolerant). All healthy boxwood plants were kept in a greenhouse until use. The plants were watered with tap water as needed and fertilized periodically with slow-release Osmocote fertilizer (Everris NA, Inc., Dublin, Ohio).

Fungal isolates, inoculum production, and plant inoculation. Two single-spored isolates of C. pseudonaviculata (CP-137 and CP-160) recovered from diseased boxwood leaves collected from a boxwood nursery in Carroll County, VA and a private property in Richmond, VA, respectively, were used in this study. Pure cultures of the isolates were maintained at $10^{\circ} \mathrm{C}$ on slants of potato dextrose agar (PDA) (Becton, Dickinson and Company, Sparks, MD) in 15-ml tubes. Prior to use, a small plug of the colonized agar from each tube was transferred to PDA in 9-cm-diameter Petri dishes. Isolates were grown for 14 to 21 days at room temperature. Three 5-mm-diameter PDA plugs from the actively growing margin of the pathogen colonies were placed onto the PDA (10 plates for each isolate) and allowed to grow for up to 2 weeks. The plates were flooded with approximately 4 to $5 \mathrm{~mm}$ of sterile deionized water (DI) for $2 \mathrm{~h}$, after which all of the mycelium was scraped off with a sterile spatula. Loose mycelium was rinsed off the agar surface until the agar was clean by flooding the plates with 4 to $5 \mathrm{~mm}$ sterile DI water, swirling the water around, and pouring it off. After rinsing four to five times, excess water was poured off and the plates were covered and incubated upside-down at 22 to $24^{\circ} \mathrm{C}$ in ambient light for up to 5 days. To harvest the freshly formed spores, the plates were held over a beaker and the surface of the culture was spritzed, with the force of the water releasing the spores into the beaker. The spore suspension (about 10 to $20 \mathrm{ml}$ ) was then recovered and shaken vigorously in a 50-ml Falcon tube to mix the suspension and separate conidia that were stuck together. The resulting stock conidial suspension was filtered through three layers of cheesecloth in order to remove any culture debris from the suspension, and the concentration of the filtrate was estimated with a hemacytometer.

Experiment 1: Effects of inoculum concentration and warm temperature. Six inoculum levels $(0,1,250,2,500,5,000,10,000$, and 20,000 spores $/ \mathrm{ml}$ ) and five temperatures $(18,23,25,27$, and $29^{\circ} \mathrm{C}$ ) were assessed. Serial dilutions of stock suspension were made to obtain the desired inoculum concentrations. At $24 \mathrm{~h}$ prior to inoculation, plants were placed inside growth chambers at designated temperatures. Three replicate plants for each dosage level were placed in two chambers, each set at one of the trial temperatures, with consecutive runs resulting in a complete replication of the entire experiment. The experiments were repeated twice. Plants were spray inoculated with conidial suspensions using a hand sprayer (PRO16RW; Contico, Bridgeton, MO) until run-off was observed. Noninoculated plants sprayed with sterile water served as the control. After inoculation, the plants were arranged in a completely randomized design inside a growth chamber (M-12; Environmental Growth Chambers, Chagrin Falls, Ohio), set at the designated temperature under a cycle of $14 \mathrm{~h}$ of light $\left(55 \mu \mathrm{mol} \mathrm{m}{ }^{-2} \mathrm{~s}^{-1}\right), 10 \mathrm{~h}$ of darkness, and $90 \%$ relative humidity (RH), and immediately covered with a wet bedsheet to increase the humidity to 98 to $100 \%$. To maintain continuous leaf wetness in the canopy, leaves were sprayed with sterile water every $4 \mathrm{~h}$. The plants were incubated for $24 \mathrm{~h}$ and subsequently transferred to a greenhouse to allow disease development. Diseased leaves on each plant were counted 7 days after inoculation. An average total number of leaves per plant was estimated from counts of a random sample of 10 plants.

Experiment 2: Effects of inoculum concentration, cultivar and leaf age. Six inoculum concentrations $(1,250,2,500,5,000,10,000$, 20,000 , and 40,000 spores $/ \mathrm{ml}$ ), four cultivars, and two leaf ages were evaluated under controlled environments. Serial dilutions of the stock suspension were made to obtain the desired inoculum concentrations. The four boxwood cultivars described above were tested. The leaf age effect was determined by categorizing leaves as young (current year flush; light green leaves at the tip of the shoot) or old (1 year old and older; dark green leaves at the base of the shoot) during a 4-month time frame of inoculation studies. Three plants of each cultivar and dosage level were incubated in two chambers $\left(23^{\circ} \mathrm{C}, 90 \%\right.$ $\mathrm{RH}$, cycle of $14 \mathrm{~h}$ of light $\left(55 \mu \mathrm{mol} \mathrm{m} \mathrm{m}^{-2} \mathrm{~s}^{-1}\right)$ and $10 \mathrm{~h}$ of darkness), resulting in a complete replication of the experiment. Plants were spray inoculated with the conidial suspensions and incubated as described above. Disease incidence was recorded on young and old leaves by counting the number of diseased leaves on each plant from 7 days after inoculation. A random sample of five plants was used to compute an estimate of average total leaf count for each cultivar.

Experiment 3: Effect of interrupted wetness periods. This set of experiments examined the effect of interrupted wetness period on infection of boxwood by $C$. pseudonaviculata. Three replicate $B$. sempervirens Suffruticosa plants were inoculated with a conidial suspension of 20,000 spores $/ \mathrm{ml}$ and subjected to interrupted and continuous wet periods of various duration in a growth chamber maintained at $23^{\circ} \mathrm{C}$ and $\mathrm{RH}$ adjusted to $100 \%$. The chambers were exposed to $14 \mathrm{~h}$ of light each day $\left(55 \mu \mathrm{mol} \mathrm{m} \mathrm{m}^{-2} \mathrm{~s}^{-1}\right)$.

In experiment $3 \mathrm{~A}$, interrupted wet-period treatments consisted of three segments: an initial 8-h wet segment and a final 12-h wet segment, interrupted by a middle dry period of various durations $(0,3,6$, $12,18,24$, and $30 \mathrm{~h}$ ). The moist chamber for the initial and final wetness period was prepared as described for the first experiment above. Once the initial wetness period of $8 \mathrm{~h}$ had finished, the inoculated plants were removed from the growth chamber and dried by placing them $90 \mathrm{~cm}$ from two low-speed fans at room temperature and about $55 \% \mathrm{RH}$ for 20 to $30 \mathrm{~min}$. After the drops had evaporated, the plants were left at room temperature outside of the chamber at $55 \% \mathrm{RH}$ (measured by a sling psychrometer; Arthur H. Thomas Company, Philadelphia) for the different periods. Dry period was defined as percent RH less than $65 \pm 5 \%$. Once each dry period had finished, leaves of the plants were rewetted by spraying the plants with sterile water, and the plants were incubated in the moist growth chamber at $100 \%$ 
RH for an additional $12 \mathrm{~h}$. Each continuous wet period (20, 23, 26, $32,38,44$, and $50 \mathrm{~h}$ ) had the same total length as its corresponding interrupted wet period. All inoculated plants were subsequently moved to the greenhouse to allow symptom development. The number of diseased leaves was recorded 7 days after inoculation. Followup experiments (3B) to confirm the results used either 8 or $5 \mathrm{~h}$ as the initial wet period.

Data analysis. For the purposes of analysis, it was assumed that each leaf on a boxwood plant (or in experiment 2 within an age class) had the same probability of infection $(p)$ and that each leaf was infected independently of any other leaf. Given these assumptions, the number of diseased leaves for a specific boxwood plant with $N$ susceptible leaves was then modeled using a binomial distribution. A negative binomial distribution with probability function:

$$
\operatorname{Pr}(N=n)=\frac{\Gamma\left(r_{c}+n\right)}{n ! \Gamma\left(r_{c}\right)}\left(\frac{\mu_{c}}{1+\mu_{c}}\right)^{n}\left(\frac{1}{1+\mu_{c}}\right)^{r_{c}}
$$

where $\mu_{c}$ can be interpreted as the average rate of increase of leaf number and $r_{c}$ represents the time that has been available for the plant's growth, was used to model the variation of $N$ within cultivar $c$. The product of $\mu_{c}$ and $r_{c}$ gives the population average value of $N$. The choice of the negative binomial distribution was based on a preliminary analysis of the total leaf counts collected for each cultivar. Combining this distribution with the binomial distribution for the count of diseased leaves and averaging over $N$ resulted in another negative binomial distribution for the count of diseased leaves with average growth rate $p \mu_{c}$ and plant growth period $r_{c}$. For the setting in which the age of the leaves was also considered, an additional parameter $(\rho)$ representing the average proportion of young leaves

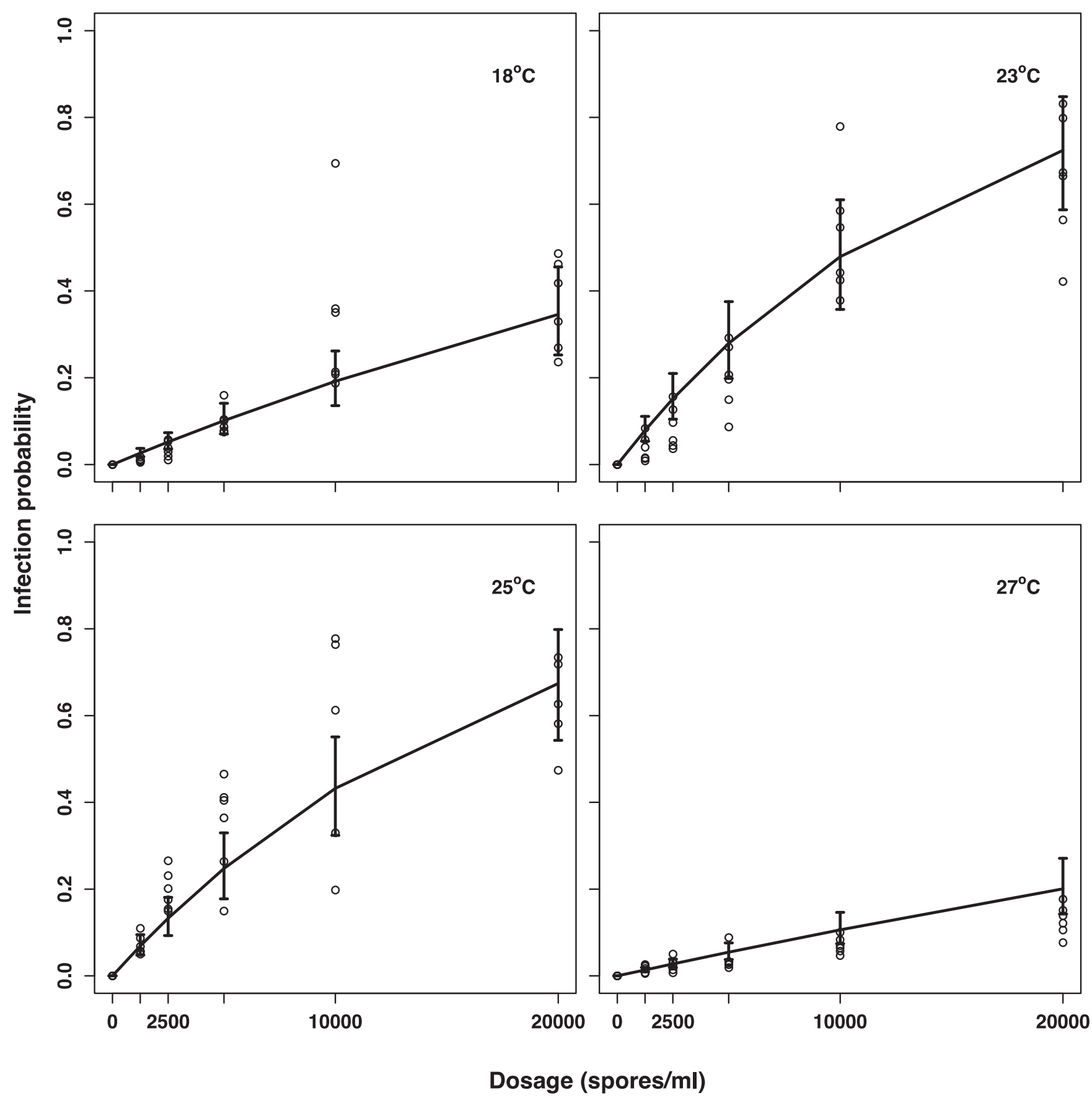

Fig. 1. Effect of temperature and inoculum concentration on infection of boxwood plants by Calonectria pseudonaviculata. Actual observations are scaled by estimated average total leaf count (575.12 leaves) and are presented as open circles. Fitted curves are based on the posterior mean of equation 1 evaluated at the Metropolis-Hastings simulated parameter values. Error bars represent point-wise $95 \%$ credible intervals. 
across all boxwood plants (for now, it is assumed that this parameter is independent of cultivar) was also incorporated and, in this case, the average growth rate was given by $p \rho \mu_{c}$ for young leaves and $p(1-\rho) \mu_{c}$ for old leaves, with both age groups having the same growth period $r_{c}$. In the analysis, $p$ will be allowed to also vary with age class.

All factor effects considered in each of the three experiments are represented through the following infection probability model:

$$
p=1-e^{-\gamma \times \text { Dosage }}
$$

where the primary source of inference is on the rate parameter $\gamma$, which controls the rate of change in the infection probability per unit of inoculum as inoculum dosage increases. The choice of this specific model form was motivated by the observed patterns in the collected data. Details regarding the specific relationship between $\gamma$ and any other factors considered in each of the experiments are provided in the sections below.

The estimation of the parameters in all of the following models is performed under a Bayesian statistical paradigm. That is, any uncertainty held by the experimenters regarding the true parameter values is represented through a prior distribution (prior for short) on the unknown parameters. These priors are then combined with the data to generate a posterior distribution (posterior for short), which represents the experimenter's new understanding and uncertainty regarding the true parameter values. It is this posterior distribution from which parameter estimates are derived. Conjugate prior distributions were either taken from known distribution families or custom created in order to best represent the effect of the parameter within the model. The parameter values of the prior distributions were chosen to reflect the observed data while also infusing the prior distributions with higher levels of uncertainty in order to allow the data a larger role in informing the parameter estimates. For example, a $\beta$ prime distribution with hyperparameters $\alpha=100$ and $\beta=6$ (yielding a prior mean odds of 20) was used as the prior distribution for $\mu_{\mathrm{c}}$ and a $\gamma$ distribution with hyperparameters $\alpha=2$ and $\beta=2$ was used as the prior distribution for $r_{c}$ (yielding a prior mean dispersion of 4). Additional prior distributions for each of the estimated parameters are provided in Supplementary Tables S1 to S3.

The Metropolis-Hastings algorithm, a Markov chain Monte Carlo simulation procedure (Chib and Greenberg 1995), was used to derive the posterior distribution for each analysis due to the model complexity. The statistical software package R (R Core Team 2014) was used to perform the analysis with a custom Metropolis-Hastings algorithm written for each analysis. The code is provided in Supplementary File S1.

Rate parameter for experiment 1, temperature, and inoculum dosage. For this experiment, the rate parameter $\gamma$ is modeled as an explicit function of temperature. The form of this function is given by

$$
\gamma_{\text {Temp }}=\gamma_{0} \exp \left\{\gamma_{1}\left(\text { Temp }-\gamma_{2}\right)-\exp \left[\gamma_{3}\left(\text { Temp }-\gamma_{2}\right)\right]\right\}
$$

and is motivated by the observed trend in the data. Here, $\gamma_{0}$ is a scaling parameter, $\gamma_{1}$ and $\gamma_{3}$ are rate parameters, and $\gamma_{2}$ helps control the location of the optimum temperature. The form of the function is a generalization of the derivative of a Gompertz function (Gompertz 1825), and appeared to best describe the observed behavior. The specific prior densities for each of the parameters are:

$$
\begin{array}{r}
f\left(\gamma_{0}\right) \propto \frac{\left(1-e^{-\gamma_{0}}\right)^{0.0001-1} e^{-\gamma_{0}}}{\left(2-e^{-\gamma_{0}}\right)^{0.0001+2}} \\
f\left(\gamma_{2}\right)=\exp \left[\left(\gamma_{2}-25.5\right)-\exp \left(\gamma_{2}-25.5\right)\right] \\
f\left(\gamma_{1}\right)=\frac{1}{0.35} \exp \left(-\frac{\gamma_{1}}{0.35}\right) \\
f\left(\gamma_{3}\right) \propto \exp \left[-\exp \left(\gamma_{3}\right)\right]
\end{array}
$$

The density in equation 5 is that of the Gumbel distribution (Gumbel 1941), also known as the type 1 extreme value distribution, and the density in equation 6 is that of an exponential distribution.
Rate parameter for experiment 2, cultivar resistance, and leaf age; and experiment 3 , interrupted wetness. For experiments 2 and 3 , the infection rate parameter $\gamma$ is treated as a constant, with an individual rate parameter for each combination of age and cultivar in experiment 2 , and each combination of wetness interruption environment (wet versus dry) and duration of interruption in experiment 3 . The reason for this choice was due to the clear categorical nature of the factors in experiment 2 and the lack of a clear functional pattern for the effect of duration in experiment 3 . The prior density in equation 4 was used for each individual rate parameter in each of these experiments.

\section{Results}

Effects of temperature and inoculum concentration. Boxwood blight incidence (BBI; number of infected leaves/plant) increased as inoculum concentration increased from $1.25 \times 10^{2}$ to $2 \times 10^{4}$ conidia/ml at four temperatures $\left(18\right.$ to $\left.27^{\circ} \mathrm{C}\right)$ after $24 \mathrm{~h}$ of incubation, with most lesions formed at 23 and $25^{\circ} \mathrm{C}$ (Fig. 1). Infection occurred at $18,23,25$, and $27^{\circ} \mathrm{C}$ but was absent at $29^{\circ} \mathrm{C}$ at all inoculum concentrations.

In addition to the scaled observed data, Figure 1 also presents the fitted curves based on the estimated model in equation 1 . For the most part, the fitted curves visually match the data rather well, with the only exceptions being the curves corresponding to temperatures 25 and $27^{\circ} \mathrm{C}$. The estimated effect of temperature on the infection rate parameter $\gamma$ along with pointwise $95 \%$ credible intervals (an interval that contains the true value with $95 \%$ probability based on the posterior distribution) is shown in Figure 2. Based on equation 3, the optimum temperature is estimated as $23.7^{\circ} \mathrm{C}$ with a $95 \%$ credible interval of 23.4 to $24^{\circ} \mathrm{C}$. The estimated threshold temperature, after which the infection probability drops to near zero, is $28^{\circ} \mathrm{C}$.

Effects of inoculum concentration, cultivar, and leaf age. As expected, Justin Brouwers yielded the highest infection probabilities, followed by Green Mound, John Baldwin, and Nana (Fig. 3). On the most susceptible cultivar, the percentage of infected leaves increased with increasing inoculum density from 1,250 to 40,000 spores/ml (Fig. 3). No infection occurred for John Baldwin, Green Mound, and Nana at inoculum doses of $\leq 5,000$ spores/ml (Fig. 3). Lesions were observed on the latter cultivars when inoculum dose exceeded 5,000 spores $/ \mathrm{ml}$, with mean disease incidence increasing slightly at higher concentrations of inoculum from 10,000 to 40,000 spores $/ \mathrm{ml}$, reaching a maximum at the highest concentration of 40,000 spores $/ \mathrm{ml}$ (Fig. 3). However, the mean disease incidence was minimal on these

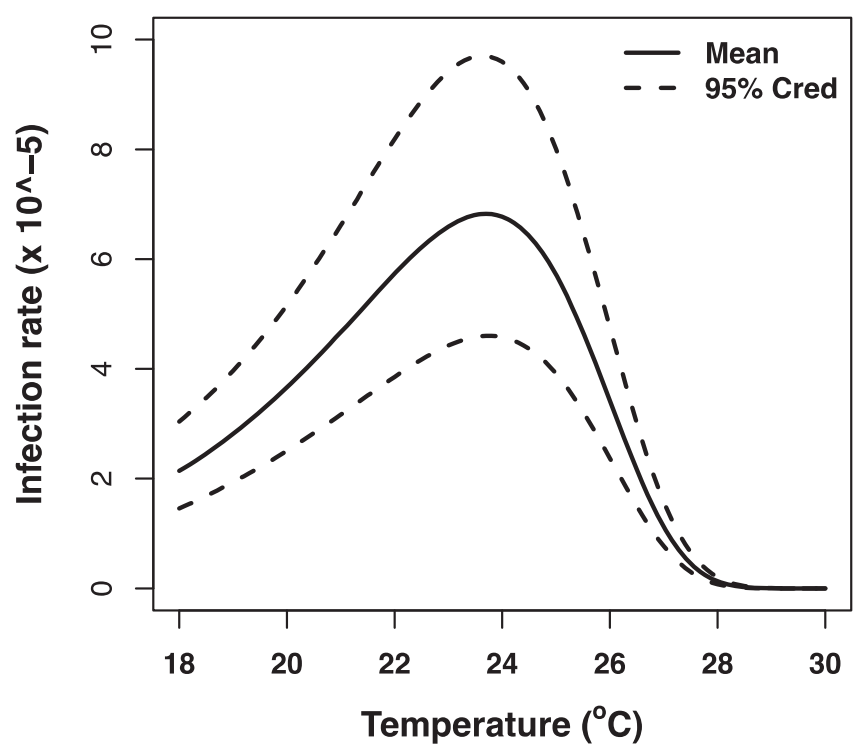

Fig. 2. Mean of the posterior distribution of the infection rate parameter $\gamma$ (equation 2) evaluated at the Metropolis-Hastings simulations with point-wise $95 \%$ credible intervals. 
cultivars compared with that observed for Justin Brouwers. A statistical comparison of cultivars and age groups is provided in Table 1. Statistical significance is determined through the use of a 95\% credible interval on the differences between groups. Should the interval contain zero, the difference is considered statistically insignificant. Justin Brouwers was significantly more susceptible than the other three cultivars, which were close to each other in susceptibility. Younger leaves were significantly more susceptible than older leaves for Justin Brouwers and Nana, whereas the older leaves were more susceptible for John Baldwin and there was no significant difference due to age for Green Mound. The fitted curves for all of the data are presented in Figure 3. Overall, the fitted curves appear to be visually reasonable.
Effect of dry interruption on infection. The data from two separate sets of interrupted-wetness experiments are shown in Figure 4 and Table 2 . In experiment $3 \mathrm{~A}$, when the middle period was dry and short (designated as $0.5 \mathrm{~h}$; plants were dried for approximately 20 to $30 \mathrm{~min}$ and then returned to wet conditions), disease incidence did not differ from that of plants held continuously wet for $20 \mathrm{~h}$. In contrast, the mere presence of a dry spell of $3 \mathrm{~h}$ or more reduced the infection probability significantly (Fig. 4; all differences between wet and dry middle periods of the same duration of $\geq 3 \mathrm{~h}$ were significant). With regards to the duration of the middle period, there were very few significant differences regardless of whether they were wet or dry; only the 6-h versus 18 -h and 18-h versus 30-h dry interruptions were significantly different, and those just barely so.
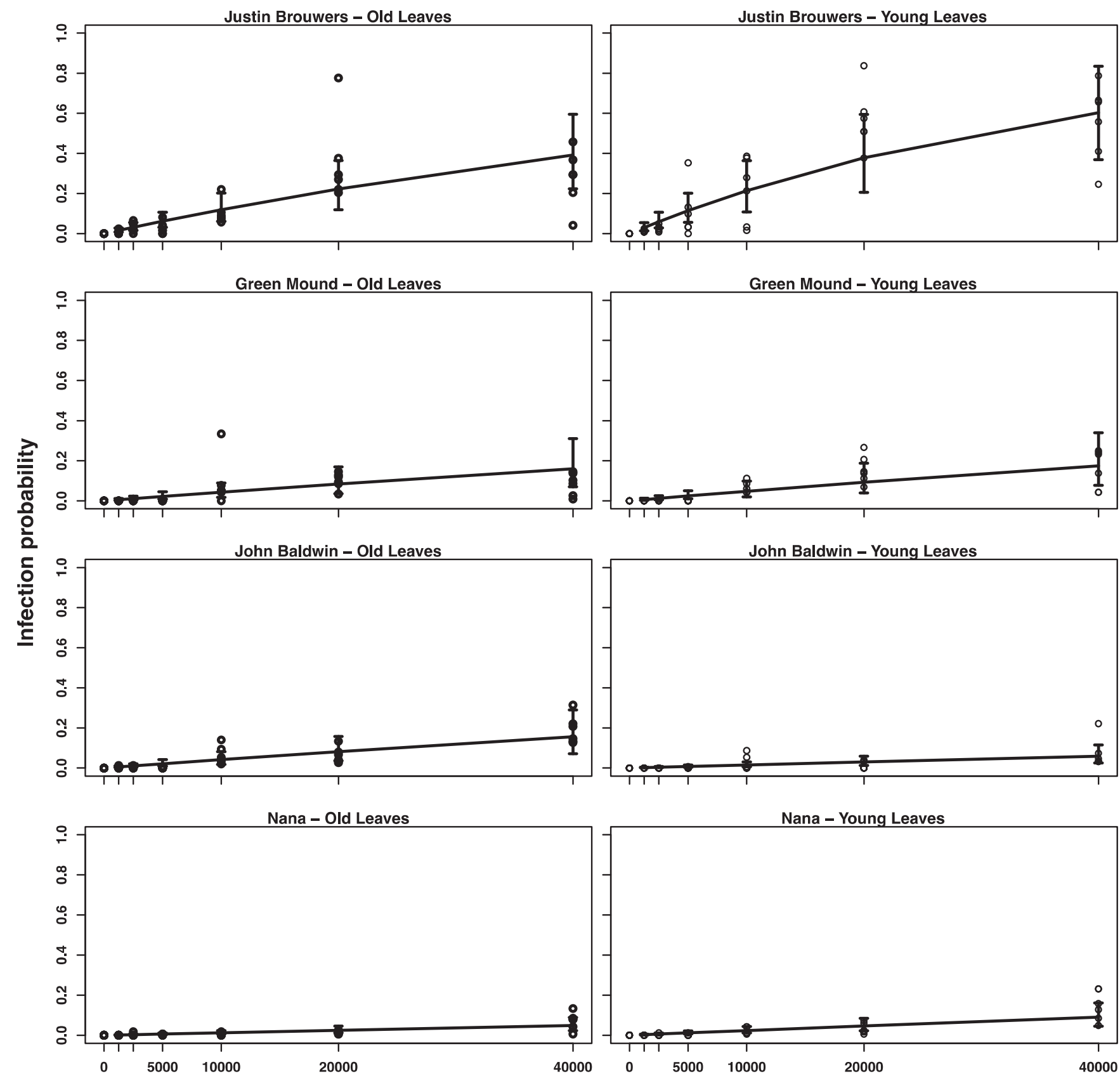

\section{Dosage (spores/ml)}

Fig. 3. Effects of cultivar and leaf age on inoculum dose-response relation of boxwood blight by Calonectria pseudonaviculata as measured by count of diseased leaves. Actual counts have been scaled by the estimated average total leaf count for each cultivar (Justin Brouwers $=244.2$, Green Mound $=232.8$, John Baldwin $=297.5$, and Nana $=330.2$ ) and are presented as open circles. Curves represent the posterior mean of the experiment 2 variation of equation 1 evaluated at the Metropolis-Hastings simulation values. Error bars represent point-wise $95 \%$ credible intervals. 
In experiment 3B (Table 2), there were few significant differences between the initial wetness periods of 5 and $8 \mathrm{~h}$, with only the dry middle period of $3 \mathrm{~h}$ resulting in a significantly lower infection probability when following a 5-h rather than an 8-h initial wet period. Compared with infection in the 5-h wet control, a 0-, 3-, and 8-h dry interruption before another $12 \mathrm{~h}$ of wetness led to an actual lesion count of 2.5, 1.0, and 1.7 times the level of infection in the control, respectively, whereas a 20 -h continuous wetness produced 11.0 times the level of infection. With $8 \mathrm{~h}$ of initial wetness, the $0-$, 3-, and 8-h dry interruption before another 12-h wetness produced 1.6, 1.4 , and 1.5 times, respectively, the number of lesions in the control, whereas $20 \mathrm{~h}$ of continuous wetness produced 5.5 times as many (Table 2). The main difference was that the 0-h dry interruption reduced infection in the two 3B experiment but not in the two 3A experiments. The duration of the dry interruption, as long as it was $3 \mathrm{~h}$ or longer, had no discernible effect in any of the experiments.

\section{Discussion}

This study advanced our understanding of the factors affecting the infection process of boxwood blight while providing critical data for improving disease forecasting models (Coop 2013).

The finding that a 3-h dry interruption drastically reduced infection highlights the importance of wetness in boxwood blight development and helps us to understand why outbreaks of this disease have been associated with long and continuous wetness, including rain events and foggy weather conditions. This result suggests that most germinated spores that have not completed the infection process did not survive the dry interruption of $3 \mathrm{~h}$ or longer and that the pathogen growth remains very limited when being wetted again. Shorter interruptions of 20 to 30 min produced more variable results: infection was not reduced in two experiments (Fig. 4) but greatly reduced in two others (Table 2). This may have been due to different degrees of drying. In our study, the dry period had an average $\mathrm{RH}$ of $65 \%$ under indoor lighting conditions, and the plants were subjected to the gentle breeze from a fan; whereas, under field conditions, desiccation of spores exposed to sunlight, fluctuating temperatures, RH, and wind speed during the interrupted wet period could occur more quickly than in a controlled environment, or its impact could be slower if skies remained overcast and humidity remained high. To what extent leaves remain wet or become dry during such short wetness interruptions in the field would be difficult to determine in a practical setting. Effects of dryness on germinated spore survival have been reported for other pathogens such as Botryosphaeria obtusa and Fusicladium eriobotryae (Arauz and Sutton 1990; González-Domínguez et al. 2013; Magarey et al. 2005). C. pseudonaviculata appears to fit in the group described by Magarey et al. (2005) as highly sensitive to wetness interruption. Therefore, it is more than likely that a current boxwood disease forecasting model with the threshold dryness period of $8 \mathrm{~h}$ for stopping the infection process (Coop 2013) overestimates disease risk. Because substantial infection occurred within the first 5 or $8 \mathrm{~h}$ of wetness, it is likely that an earlier dry interruption, following a shorter initial wet period may cause even more disease reduction than those studied here. Further studies may be warranted to assess the effects of such conditions on the infection by $C$. pseudonaviculata and to determine the minimal dry period required to stop the infection.

The optimum and maximum temperatures for infection of boxwood blight by $C$. pseudonaviculata were 23.7 and $28^{\circ} \mathrm{C}$, respectively. These results generally agree with previous in vitro studies in which mycelial growth of the pathogen was found at the optimum temperature at $25^{\circ} \mathrm{C}$ and the maximum near $30^{\circ} \mathrm{C}$ (Douglas 2012; Gehesquière 2014; Henricot 2006). Our results complement those of Gehesquière (2014), who included the highest temperature at $22.4^{\circ} \mathrm{C}$ because the weather conditions in Belgium generally are much cooler than in the southeastern United States. The average maximum temperature in Brussels, Belgium for June through August is $21.6^{\circ} \mathrm{C}$ and the average minimum is $12.8^{\circ} \mathrm{C}$, whereas equivalent

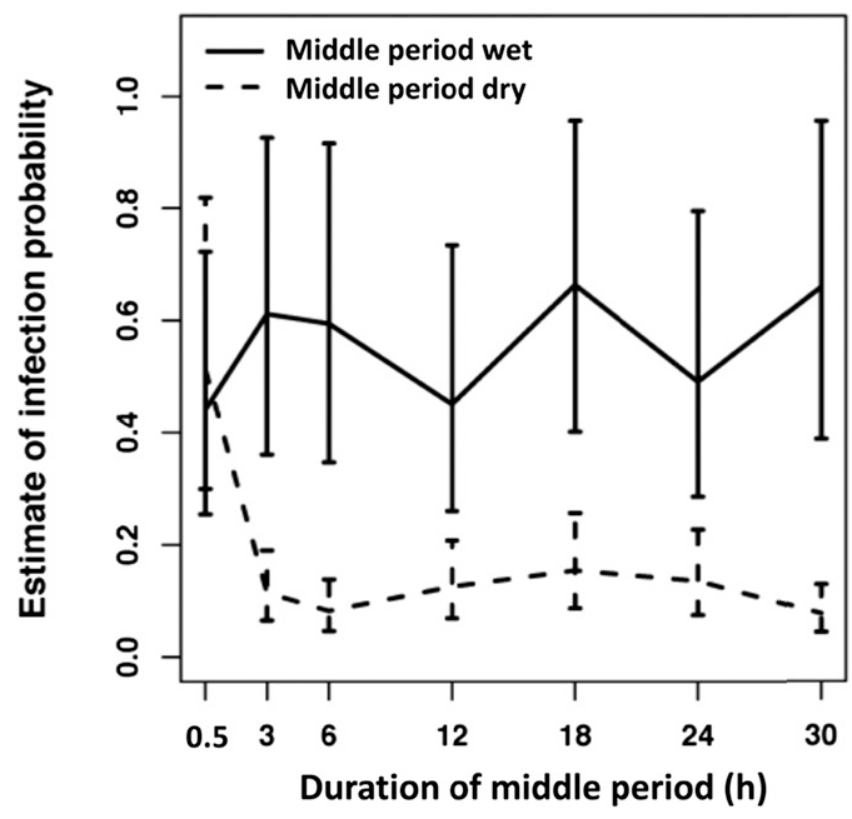

Fig. 4. Posterior means of infection probability from continuous and interrupted wet periods. Error bars represent point-wise $95 \%$ credible intervals. Data are from two separate experiments with an 8-h initial wet period followed by middle periods (wet or dry) of the durations shown, followed by a final period of $12 \mathrm{~h}$ of wetness.

Table 1. Parameter estimates for experiment 2: inoculum dose, cultivar, and leaf age on boxwood blight infection ${ }^{\mathrm{x}}$

\begin{tabular}{|c|c|c|c|}
\hline Model parameter ${ }^{\mathbf{y}}$ & Posterior mean $(95 \%$ CI $)$ & Old $\left(\times 10^{-6}\right)(95 \% \mathrm{CI})^{\mathrm{z}}$ & Young $\left(\times 10^{-6}\right)(95 \% \mathrm{CI})^{\mathrm{z}}$ \\
\hline$\mu_{J U S}$ Justin Brouwers & $111(65-203)$ & $\ldots$ & $\ldots$ \\
\hline$\mu_{G M}$ Green Mound & $199(101-388)$ & $\ldots$ & $\ldots$ \\
\hline$\mu_{J B}$ John Baldwin & $201(105-402)$ & $\ldots$ & $\ldots$ \\
\hline$\mu_{N A}$ Nana & $137(71-268)$ & $\ldots$ & $\ldots$ \\
\hline$r_{J U S}$ Justin Brouwers & $2.20(1.46-3.16)$ & $\ldots$ & $\ldots$ \\
\hline$r_{G M}$ Green Mound & $1.17(0.67-1.87)$ & $\ldots$ & $\ldots$ \\
\hline$r_{J B}$ Justin Brouwers & $1.48(0.80-2.47)$ & $\ldots$ & $\ldots$ \\
\hline$r_{N A}$ Nana & $2.41(1.30-3.96)$ & $\ldots$ & $\ldots$ \\
\hline$\rho_{Y}$ & $0.50(0.43-0.57)$ & $\ldots$ & $\ldots$ \\
\hline$\gamma$ Justin Brouwers* & $\ldots$ & $12.8(6.3-22.6) \mathrm{A}$ & $24.4(11.5-45.1) \mathrm{A}$ \\
\hline$\gamma$ Green Mound & $\ldots$ & $4.4(1.8-9.3) \mathrm{B}$ & $4.9(2.0-10.6) \mathrm{B}$ \\
\hline$\gamma$ John Baldwin* & $\ldots$ & $4.3(1.9-8.6) \mathrm{B}$ & $1.5(0.7-3.1) \mathrm{C}$ \\
\hline$\gamma$ Nana* $^{*}$ & $\ldots$ & $1.2(0.6-2.3) \mathrm{C}$ & $2.4(1.2-4.4) \mathrm{BC}$ \\
\hline
\end{tabular}

${ }^{\mathrm{x}}$ Estimates for $\gamma$ specific to cultivar and leaf age with corresponding $95 \%$ credible intervals (CI).

y Parameters: $\mu=$ rate of increase in leaf number, $r=$ time plant has had to grow, $\rho=$ proportion of young (current-year) leaves, and $\gamma=$ infection rate parameter per unit of inoculum. Asterisks (*) indicate significant difference between old and young leaves.

${ }^{\mathrm{z}}$ For posterior means for old and young leaves, different letters following values indicate significant differences within columns. Data followed by the same letter are judged not significantly different when the $95 \%$ CI of the difference does not include 0 . 
values for Richmond, VA are 6.6 to $9.4^{\circ} \mathrm{C}$ higher (average maximum of $31.0^{\circ} \mathrm{C}$ and minimum of $21.6^{\circ} \mathrm{C}$; data from $\mathrm{http}$ ://www.worldweather. org/en/home.html). Our study fills a knowledge gap that is important for understanding and calibrating the boxwood blight forecasting model for warmer regions, such as the southeastern United States. The current disease forecasting model, with the upper temperature threshold of $29.4^{\circ} \mathrm{C}$ for infection and the use of degree-hours (Coop 2013), assumes that infection increases up to that limit. Disease risk at higher temperatures can now be estimated more accurately but still requires validation with field data of disease dynamics as related to weather conditions.

Inoculum concentration is an important factor influencing boxwood blight development; more $C$. pseudonaviculata inoculum results in more disease. Similar results were reported by Dart et al. (2015), who found that percent leaf blight in boxwood shoots coated with $C$. pseudonaviculata-infested soil increased with increasing concentration of microsclerotia or conidia present in the soil. In $C$. pteridis infecting eucalypt leaves, percentage leaf area with lesions and defoliation linearly increased with the increase in inoculum concentration (Graça et al. 2009). Recent field studies (data not shown) have suggested that inoculum availability following prolonged dry periods may be a critical limiting factor in the disease progress by C. pseudonaviculata.

Differences between cultivars in our single-infection cycle experiment were modest, and similar in magnitude to the differences observed in greenhouse and outdoor trials (Ganci 2014; Gehesquière 2014; Shishkoff et al. 2015). On the one hand, even low levels of susceptibility can be a practical problem if they allow plants with nonconspicuous infections to be introduced in previously noncontaminated sites (Ganci 2014); on the other hand, modest differences in resistance would be expected to be amplified in field situations where polycyclic increase takes place (Zadoks and Schein 1979). Graça et al. (2009) showed that leaf blight and defoliation of eucalypts caused by $C$. pteridis can be significantly influenced by host genotype, leaf wetness period after inoculation, plant age, and phenological leaf stage. Our data on the effects of leaf age indicated that young leaves were more susceptible than older leaves for two cultivars tested but that, for John Baldwin, older leaves were more susceptible than younger leaves. Our results were obtained at optimum conditions, with a constant temperature of $23^{\circ} \mathrm{C}$ and a fixed leaf wetness duration of $24 \mathrm{~h}$. Gehesquière (2014) analyzed the effect of various leaf wetness durations on $C$. pseudonaviculata infection of highly susceptible (English boxwood) and susceptible (common boxwood) cultivars, and found that the minimum leaf wetness period for infection was cultivar dependent and that, within each cultivar,

Table 2. Comparison of continuous and interrupted wet periods on boxwood blight infection (experiment $3 \mathrm{~B})^{\mathrm{y}}$

\begin{tabular}{lccrc}
\hline $\begin{array}{l}\text { Initial wet } \\
\text { period (h) }\end{array}$ & $\begin{array}{c}\text { Middle dry } \\
\text { period (h) }\end{array}$ & $\begin{array}{c}\text { Final wet } \\
\text { period (h) }\end{array}$ & Mean $^{\mathbf{z}}$ & $\mathbf{9 5 \% ~ C I}$ \\
\hline 5 & 0 & 0 & $8.5 \mathrm{C}$ & $4.9-14.3$ \\
5 & 0 & 12 & $169.5 \mathrm{~A}$ & $81.5-320.9$ \\
5 & 0.5 & 12 & $25.0 \mathrm{~B}$ & $13.2-47.0$ \\
5 & 3 & 12 & $8.2 \mathrm{C}$ & $4.8-14.0$ \\
5 & 8 & 12 & $15.1 \mathrm{BC}$ & $8.5-26.7$ \\
8 & 0 & 0 & $13.3 \mathrm{~B}$ & $7.4-23.3$ \\
8 & 0 & 12 & $136.7 \mathrm{~A}$ & $58.9-283.0$ \\
8 & 0.5 & 12 & $22.9 \mathrm{~B}$ & $12.3-42.4$ \\
8 & 3 & 12 & $19.1 \mathrm{~B}$ & $10.4-34.7$ \\
8 & 8 & 12 & $21.6 \mathrm{~B}$ & $11.9-39.9$ \\
\hline
\end{tabular}

y Data from one experiment with $5 \mathrm{~h}$ and one with $8 \mathrm{~h}$ or initial wetness, followed by a middle dry period of the durations shown, followed by a final period of $12 \mathrm{~h}$ of wetness. Data followed by the same letter are judged not significantly different when the $95 \%$ credible interval (CI) of the difference does not include 0 . Data for 5- and 8-h initial wetness analyzed separately; when compared with each other, only treatments with the 3 -h middle period gave a significant difference between the initial wet periods of 5 and $8 \mathrm{~h}$.

${ }^{\mathrm{z}}$ Posterior mean of $\gamma$ on $10^{-6}$ scale, where $\gamma=$ infection rate parameter per unit of inoculum. this period was generally shorter for young leaves than for mature leaves, although he also observed that, under outdoor conditions for some cultivars, susceptibility of young leaves could be less than that of mature leaves. In C. pteridis of eucalypts, plant age significantly affected infection in eucalypt clones, with older plants being more susceptible than younger plants (Graça et al. 2009). Scanning electron microscope analysis suggested no difference in number of penetrations by germ tubes of $C$. pteridis between young and old leaves, although more stomata were found in young leaves (Graça et al. 2009). Resistance in young leaves was thought to be related to mechanisms that act after pathogen penetration. Differences in pattern of stomatal distribution in Eucalyptus spp. and modes of penetration of associated Calonectria spp. through either stomata, epidermal cells, or appressorium formation were also found (Graça et al. 2009). Studying whether or not such differences exist in leaves of boxwood cultivars could provide an explanation for why they may interact differently with regard to leaf age. More quantitative data on less susceptible cultivars in various temperature and wetness conditions will be needed to better determine the conditions required for successful $C$. pseudonaviculata infection in relation to host resistance, leaf age, and prevailing weather parameters. Planting and production of more resistant boxwoods clearly appear to be preferred options to reduce damage by the boxwood blight; therefore, data from such studies will ultimately be useful to tailor disease forecasts and spray programs based on the levels of resistance expressed in a specific cultivar.

\section{Acknowledgments}

We thank Saunders Brothers Nursery for providing boxwood plants used in this study and acknowledge the financial support provided by the 2008 Farm Bill for the fy13 project (13-8130-0282-CA) and the 2014 Farm Bill for the fy14 project (14-8130-0282-CA) through the United States Department of Agriculture-Animal and Plant Health Inspection Service.

\section{Literature Cited}

Arauz, L. F., and Sutton, T. B. 1990. Effect of interrupted wetness periods on spore germination and apple infection by Botryosphaeria obtusa. Phytopathology 80 : $1218-1220$

Baudoin, A., Avenot, H. F., Edwards, T. P., Diallo, Y., and Lucernoni, C. B. 2015 Evaluation of fungicides for control of boxwood blight, 2014. Plant Dis. Manage. Rep. 9:OT006.

Chib, S., and Greenberg, E. 1995. Understanding the Metropolis-Hastings algorithm. Am. Stat. 49:327-335.

Coop, L. 2013. Brief Documentation for Boxwood Blight Infection Risk Model Online publication. Oregon State University. http://uspest.org/wea/Boxwood_ blight_risk_model_summary.pdf

Crous, P., Groenewald, J., and Hill, C. 2002. Cylindrocladium pseudonaviculatum sp. nov. from New Zealand, and new Cylindrocladium records from Vietnam. Sydowia 54:23-34

Dart, N., Arrington, S., and Weeda, S. 2012. Flaming to reduce inocula of the boxwood blight pathogen, Cylindrocladium pseudonaviculatum, in field soil Online publication. Plant Health Prog. doi:10.1094/PHP-2012-1026-01-BR

Dart, N., Hong, C., and Bradley, W. T. 2014. An improved leaf disc bioassay for detecting Calonectria pseudonaviculata in soil and potting media. Plant Dis. 98:1626-1631.

Dart, N. L., Hong, C., Craig, C. A., Fry, J., and Hu, X. 2015. Soil inoculum production, survival and infectivity of the boxwood blight pathogen, Calonectria pseudonaviculata. Plant Dis. 99:1689-1694.

De Wolf, E. D., and Isard, S. A. 2007. Disease cycle approach to plant disease prediction. Annu. Rev. Phytopathol. 45:203-220.

Douglas, S. M. 2012. Boxwood blight-A new disease for Connecticut and the U.S. Online publication. The Connecticut Agricultural Experiment Station. http:// www.ct.gov/caes/lib/caes/documents/publications/fact_sheets/plant_pathology_ and_ecology/boxwood_blight-_a_new_disease_for_connecticut_and_the_u.s._1208-11.pdf

Elmhirst, J. F., and Auxier, B. E. 2013. First report of box blight caused by Cylindrocladium pseudonaviculatum (C. buxicola) in British Columbia, Canada. Plant Dis. 97:559.

Ganci, M., Benson, D., and Ivors, K. 2013. Susceptibility of commercial boxwood cultivars to Cylindrocladium buxicola, the causal agent of box blight. (Abstr.) Phytopathology 103:S2.47.

Ganci, M. L. 2014. Investigation of host resistance in Buxus species to the fungal plant pathogen Calonectria pseudonaviculata (= Cylindrocladium buxicola), the causal agent of boxwood blight and determination of overwinter pathogen survival. MS thesis, North Carolina State University Raleigh, NC.

Gehesquière, B. 2014. Cylindrocladium buxicola nom. cons. prop.(syn. Calonectria pseudonaviculata) on Buxus: Molecular characterization, 
epidemiology, host resistance and fungicide control. Ph.D. dissertation, Ghent University, Ghent, Belgium.

Gehesquière, B., D’Haeyer, S., Pham, K., Van Kuik, A., Maes, M., Höfte, M., and Heungens, K. 2013. QPCR assays for the detection of Cylindrocladium buxicola in plant, water, and air samples. Plant Dis. 97:1082-1090.

Gompertz, B. 1825. On the nature of the function expressive of the law of human mortality, and on a new mode of determining the value of life contingencies. Philos. Trans. R. Soc. Lond. 115:513-583.

González-Domínguez, E., Rossi, V., Armengol, J., and García-Jiménez, J. 2013. Effect of environmental factors on mycelial growth and conidial germination of Fusicladium eriobotryae, and the infection of loquat leaves. Plant Dis. 97:1331-1338.

Graça, R. N., Alfenas, A. C., Maffia, L. A., Titon, M., Alfenas, R. F., Lau, D., and Rocabado, J. M. A. 2009. Factors influencing infection of eucalypts by Cylindrocladium pteridis. Plant Pathol. 58:971-981.

Gumbel, E. J. 1941. The return period of flood flows. Ann. Math. Stat. 12:163-190.

Henricot, B. 2006. Box blight rampages onwards: The latest news on the spread and control of a devastating disease. Plantsman 5:153-157.

Henricot, B., and Culham, A. 2002. Cylindrocladium buxicola, a new species affecting Buxus spp., and its phylogenetic status. Mycologia 94:980-997.

Henricot, B., David, J., Ivors, K., Heungens, K., Spooner, B., Pérez Sierra, A., and Daughtrey, M. L. 2012. Proposal to conserve the name Cylindrocladium buxicola against $C$. pseudonaviculatum (Ascomycota). Taxon 61:1119-1120.

Henricot, B., Gorton, C., Denton, G., and Denton, J. 2008. Studies on the control of Cylindrocladium buxicola using fungicides and host resistance. Plant Dis. 92: 1273-1279.

Henricot, B., Pérez Sierra, A., and Prior, C. 2000. A new blight disease on Buxus in the UK caused by the fungus Cylindrocladium. Plant Pathol. 49:805.

Henricot, B., and Wedgwood, E. 2013. Evaluation of foliar fungicide sprays for the control of boxwood blight, caused by the fungus Cylindrocladium buxicola. Online publication. Plant Health Prog. doi:10.1094/PHP-2013-1024-01-RS

Iriarte, F., Paret, M., Knox, G., Schubert, T., Jeyaprakash, A., and Davison, D. 2016. First report of boxwood blight caused by Calonectria pseudonaviculata in Florida. Plant Health Prog. 17:229-231.

Ivors, K. L., Lacey, L. W., and Ganci, M. L. 2012b. Evaluation of fungicides for the prevention of boxwood blight, 2012. Plant Dis. Manage. Rep. 7:OT014.
Ivors, K. L., Lacey, L. W., Milks, D. C., Douglas, S. M., Inman, M. K., Marra, R. E., and LaMondia, J. A. 2012a. First report of boxwood blight caused by Cylindrocladium pseudonaviculatum in the United States. Plant Dis. 96: 1070 .

LaMondia, J. 2014. Fungicide efficacy against Calonectria pseudonaviculata, causal agent of boxwood blight. Plant Dis. 98:99-102.

LaMondia, J. 2015. Management of Calonectria pseudonaviculata in boxwood with fungicides and less susceptible host species and varieties. Plant Dis. 99: 363-369.

Magarey, R., Sutton, T., and Thayer, C. 2005. A simple generic infection model for foliar fungal plant pathogens. Phytopathology 95:92-100.

Malapi-Wight, M., Hebert, J. B., Buckley, R., Daughtrey, M. L., Gregory, N. F. Rane, K., Tirpak, S., and Crouch, J. A. 2014. First report of boxwood blight caused by Calonectria pseudonaviculata in Delaware, Maryland, New Jersey and New York. Plant Dis. 98:698.

R Core Team. 2014. R: A Language and Environment for Statistical Computing. R Foundation for Statistical Computing, Vienna.

Ridley, G. 1998. New plant fungus found in Auckland box hedges. Forest Health News $77: 1$.

Shishkoff, N., Daughtrey, M., Aker, S., and Olsen, R. T. 2015. Evaluating boxwood susceptibility to Calonectria pseudonaviculata by inoculating cuttings from the National Boxwood Collection at the US National Arboretum. Plant Health Prog. 16:11-15.

Van Laere, K., Hermans, D., Leus, L., and Van Huylenbroeck, J. 2011. Genetic relationships in European and Asiatic Buxus species based on AFLP markers, genome sizes and chromosome numbers. Plant Syst. Evol. 293:1-11.

Ward Gauthier, N. A., Amsden, B., Beale, J., and Dixon, E. 2016. First report of boxwood blight caused by Calonectria pseudonaviculata in Kentucky. Plant Dis. 100:1019

Weeda, S. M., and Dart, N. L. 2012. Histological evidence that microsclerotia play a significant role in disease cycle of the boxwood blight pathogen in southeastern United States and implications for disease mitigation. Online publication. Plant Health Prog. doi:10.1094/PHP-2012-0403-01-BR

Zadoks, J. C., and Schein, R. D. 1979. Epidemiology and Plant Disease Management. Oxford University Press, New York. 